\title{
Dacryolith formation around an eyelash retained in the lacrimal sac
}

\author{
JEFFREY L. JAY AND WILLIAM R. LEE \\ From the Tennent Institute of Ophthalmology, University of Glasgow, Glasgow
}

Chronic dacryocystitis with mucocele of the lacrimal sac is common in cases of epiphora, but the initial factor causing obstruction of the nasolacrimal duct often remains uncertain and pathological examination of excised lacrimal sac tissue commonly shows a chronic, non-specific inflammatory reaction. On rare occasions a dacryolith has been found within the inflamed sac but most of these dacryoliths have occurred in association with mycotic infection and usually accompany the more common canalicular concretions (DukeElder, 1974). Four cases have been reported in which Candida albicans infection was considered the initiating factor (Fine and Waring, 1947; Wolter, Stratford, and Hamell, 1956; Wolter and Deitz, 1963), but Jones (1965) failed to find any evidence of yeast-like cells in 25 casts from cases of naso-lacrimal obstruction. In one case of argyrosis reported by Grönvall (1944), a laminated dacryolith had formed round a black central nidus of silver salts; from another patient, Kofler (I94I) described a stone with coarse scaly masses at its centre.

It is possible that the initiating factor could be the presence of a lash trapped in the lacrimal sac. The following report describes such a case.

\section{Case report}

A 55-year-old man had complained for io months of a watering and irritable left eye. The condition began with pain at the inner canthus and there was a profuse yellow discharge. The yellow discharge was only partly controlled by antibiotic drops.

Examination revealed a palpable mucocele of the lacrimal sac and digital compression produced mucopurulent reflux from the puncta. Syringing of the lacrimal passages and macrodacrocystography confirmed the site of obstruction at the lower extremity of a distended sac. The control film showed no evidence of calcification within the lacrimal apparatus and no filling defect was detectable in the contrast medium filling the dilated sac. A mixed growth of coagulase positive staphylococci and diphtheroids was cultured from the discharge.

Address for reprints: J. L. Jay, Tennent Institute of Ophthalmology, Western Infirmary, 38 Church Street, Glasgow Gi I 6NT
Dacryocystorhinostomy was performed and when the lacrimal sac was incised, copious mucus spilled out to reveal an elongated yellow dacryolith which was impacted in the upper end of the naso-lacrimal duct. This was submitted to pathological examination together with the excised posterior flaps of the sac wall and nasal mucosa.

The patient had no further symptoms and was discharged from supervision four weeks after the operation.

\section{PATHOLOGICAL FINDINGS}

The biopsies of the sac wall showed ulceration of the mucosa and non-specific inflammatory infiltration of the fibrotic wall. The nasal mucosa contained a scattered lymphocytic infiltrate.

The dacryolith was Y-shaped $(6 \times 1 \mathrm{~mm})$ and the surface was nodular (Fig. I). Microscopical examination revealed a hair in the centre of one limb of the Y-shaped structure which was otherwise composed of layers of basophilic granular and eosinophilic homogeneous material interposed with layers of polymorphonuclear leucocytes and lymphocytes (Fig. 2). In Gram-stained sections bacteria were seen as Gram-positive cocci ( $\mathrm{r}$ m diameter) in chains (Fig. 2 insert). An additional feature was the presence of yeast-like structures $(2-4 \mu \mathrm{m}$ diameter) which stained with periodic acid-Schiff stain and had a clear capsule (Fig. 3). The alizarin and von Kossa stains for calcium were equivocal although the appearance of the basophilic granular material in the matrix was suggestive of dystrophic calcification.

In an attempt to clarify the structure of the dacryolith

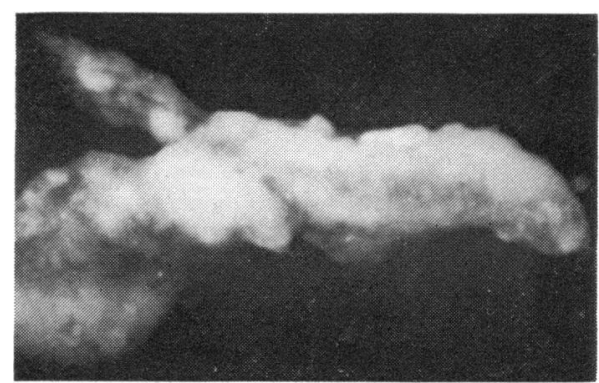

FIG. I The gross appearance of dacryolith showing $Y$-shaped bifurcation and nodular surface. $\times$ 10 

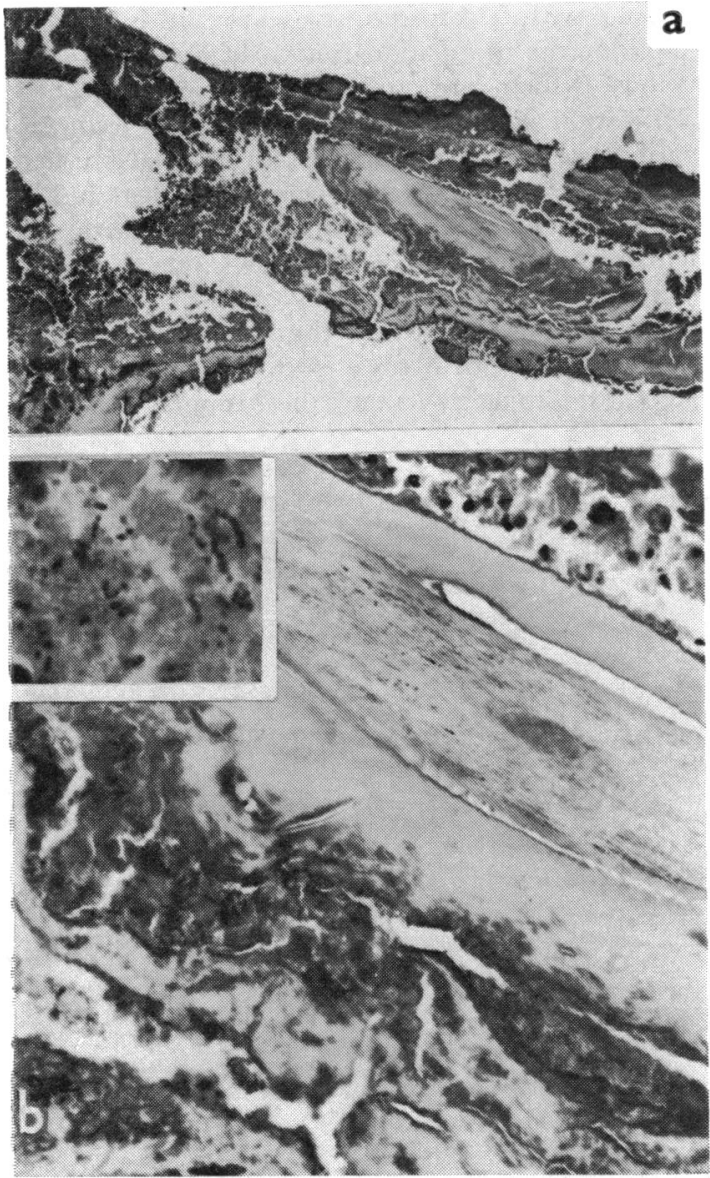

FIG. 2 (a) $A$ low power view of dacryolith showing the hair in centre of specimen. Haematoxylin and eosin. $\times$ 40. (b) $A$ higher power showing edge of the hair, lamination of hyaline material and inflammatory cells. Haematoxylin and eosin. $\times 250$. Insert shows cocci in granular debris. Gram. $\times 1000$

further, the remainder of the tissue was removed from the paraffin block and processed for electron microscopy, using the technique described by Jensen (1974).

In the tissue available for study, lymphocytes and polymorphonuclear leucocytes were identified, but many of these cells were degenerate and in some areas there were circular bodies of vesicular and granular nature which could have been derived from cell breakdown (Fig. 4). Elsewhere the ground substance was amorphous but was lined by a zone of granular electrondense material. Hydroxyapatite crystals were not identified in the electron-dense zones (Figs 4 and 5).

The yeast cells were surrounded by an electronlucent zone which was probably a retraction artefact because elements of the capsule could be identified in these spaces. The cell wall was thin (approximately $5 \mathrm{~mm}$ ) and the cell membrane was invaginated. The detail of the cytoplasmic organelles and nuclei was lost although occasional mitochondria could be identified. The dimensions of these organisms were similar to those described for Candida sp. (see Carbonell, 1971). Bacterial forms were not present in this region of the material.

\section{Discussion}

In patients who complain of conjunctival irritation it is not uncommon to find an eyelash within one

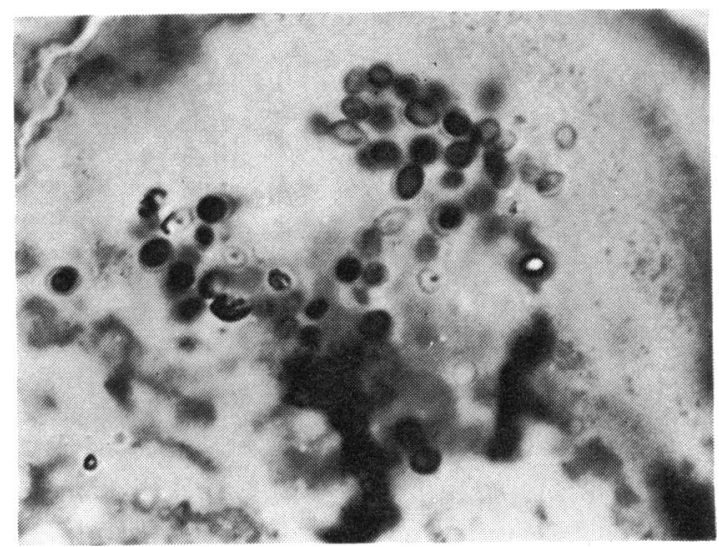

FIG. 3 Yeast-like organism surrounded by hyaline material. Note the clear capsule. Periodic acid-Schiff. $\times 1000$

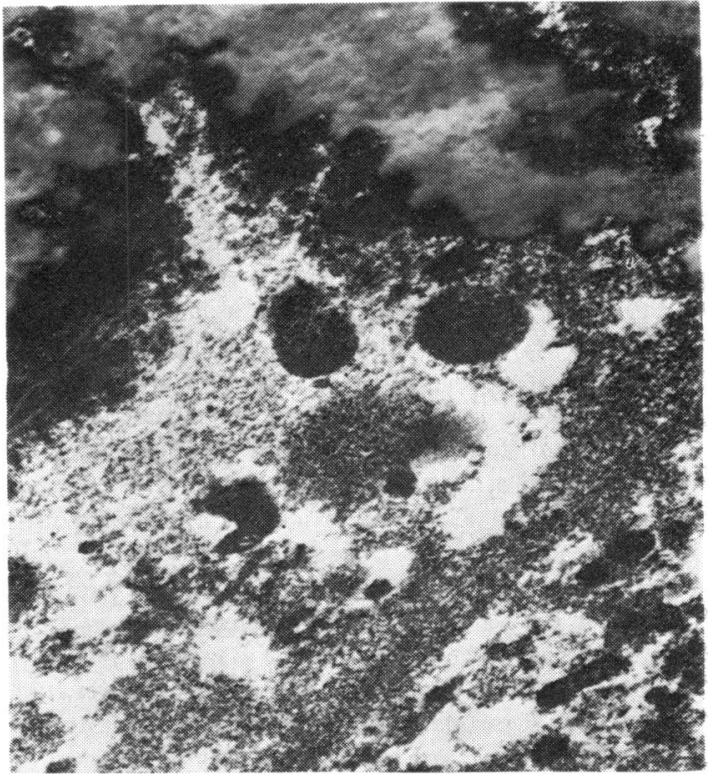

FIG. 4 Electron micrograph showing amorphous material with electron-dense border. Ground substance (below) has granular and fibrillar consistency and contains round bodies which are probably cellular breakdown products. $\times 3000 \mathrm{c}$ 


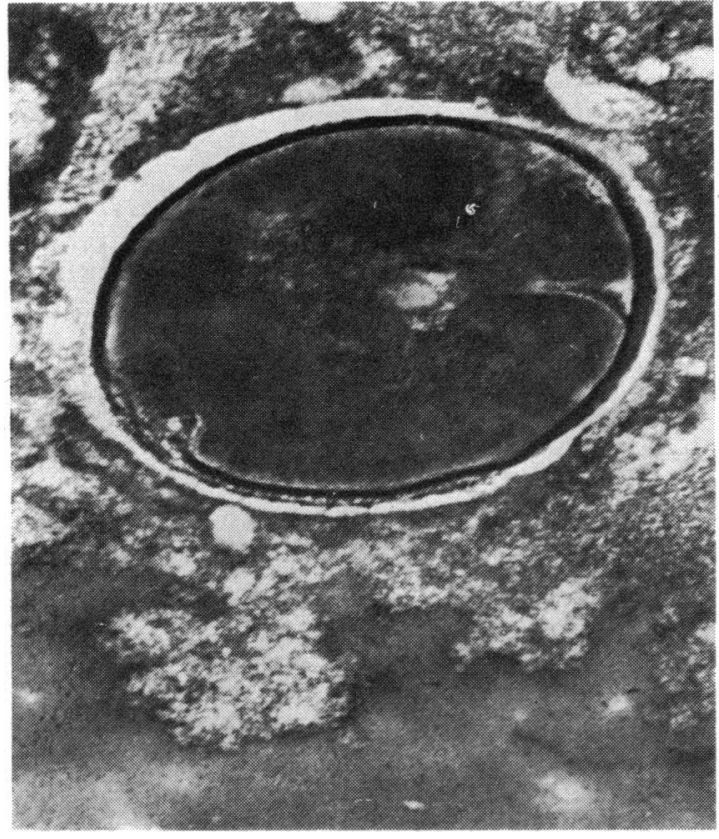

FIG. 5 Electron micrograph of a yeast within fibrillar and granular ground substance, amorphous component of the ground substance is shown below. $\times 35000$

of the lacrimal canaliculi. The end of the lash projects from the punctum and rubs on the adjacent bulbar conjunctiva. We have seen two examples of this type of conjunctival irritation and Boase (1949) reported a similar case with a localized granulomatous reaction in the conjunctiva. Cilia have been found very rarely in the lacrimal sac although it is possible that they may either be destroyed by an acute inflammatory reaction within the sac or continue downwards and escape into the nose. Some support for the latter hypothesis is produced by Gundersen (1942) who described a cast containing a cilium which had been blown out of the nose in a case of naso-lacrimal obstruction. One of the casts described by Jones (1965) also contained a lash.

The histological examination of the dacryolith provided similar information to that previously described (Duke-Elder, 1974). There is general agreement that a foreign body, in association with secondary inflammation, acts as a nidus for deposition of various types of material-for example, fibrin, cellular breakdown products, bacteria, fungi, and mucoprotein substances-and it is assumed that the last acts as a ground substance for calcium deposition. The ultrastructural variations in the matrix support the concept that there is wide chemical variation in the layers of the dacryolith. Although precise chemical identification is not possible with electron microscopy, it is a valid. technique for the demonstration of hydroxyapatite crystals which are participating in dystrophic calcification. It is therefore of interest that hydroxyapatite was not identified in the material studied, so that if calcification were occurring it was unlikely to be by the mechanisms association with cell. mediated calcification (Anderson and Reynolds, 1973).

The demonstration that the Candida sp. organisms were confined to a localized zone of the dacryolith suggests that the fungal infection.

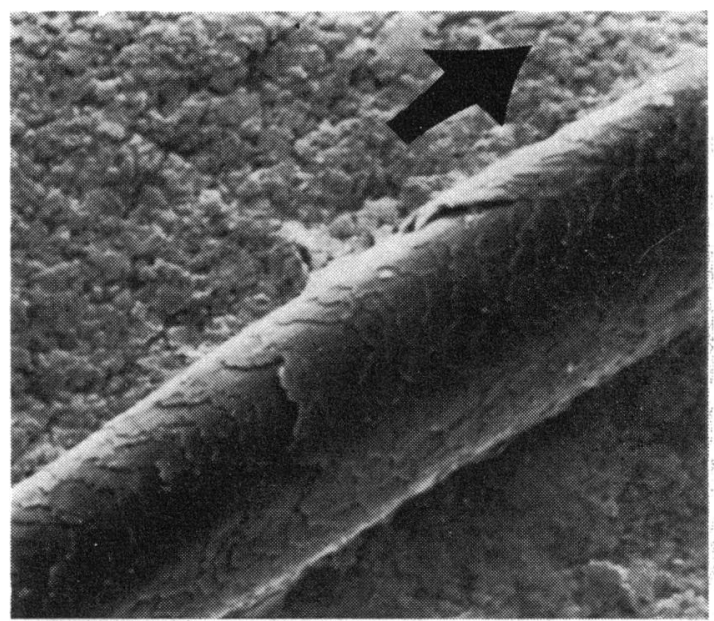

$(6 a)$

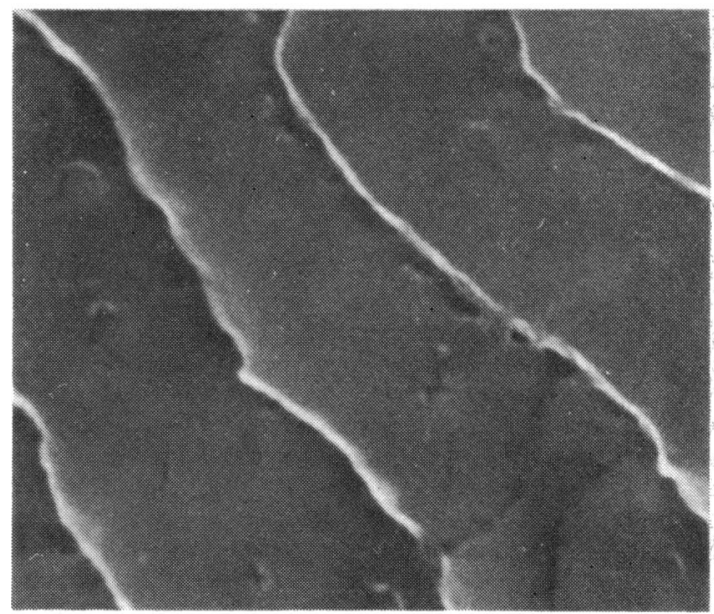

$(6 b)$

FIG. 6 Scanning electron micrographs of surface of a human eyelash. (a) Low power view of hair shaft. $\times 600$. (b) A higher magnification to show the stepped ridges which impart preferential movement in direction of arrow. $\times 3000$ 
occurred at a specific time in the evolution of the dacryolith.

It is interesting to speculate how a pliable lash is able to enter the punctum and pass onwards into the canaliculus. Stern (1952) noted that a lash is thicker than the narrowest part of the canaliculus and he suggested that the lash might be sucked along the canaliculus.

It seems more likely that the movement in the canaliculus is the result of the surface features of the hair itself. The surface structure of a human eyelash can easily be demonstrated by scanning electron microscopy (Fig. 6). The illustration shows an imbricated surface resembling the overlapping scales on a fish. This dictates a preferential direction of movement towards the root end of the lash as indicated by the arrow in Fig. 6. A simple demonstration may be performed by placing a hair between the two index fingers and rubbing gently to and fro along the length of the hair. It will always move towards its root. Although most reports of eyelashes found in the lacrimal canaliculi do not specify which end of the lash had entered first, the root was leading in the cases seen by the authors and those described by Stern (1952) and illustrated by Werb (197r).

\section{Summary}

A dacryolith was discovered in the lacrimal sac during a dacryocystorhinostomy for chronic dacryocystitis in which there was mucocele formation. Morphological examination confirmed the presence of an eyelash at the centre of the stone and electron microscopy demonstrated the presence of fungi (Candida sp.) in a matrix which was of markedly variable morphology.

The mechanism by which a hair enters the punctum and passes along the canaliculus may be attributed to the step-like pattern of ridges on the surface of a hair. The directional nature of these ridges dictates preferential movement towards the root end of the hair and prevents movement in the opposite direction.

\section{References}

ANDERSON, H. C., and REYNOLDS, J. J. (1973) Develop. Biol., 34, 2 I I

BOASE, A. J. (1949) Brit. F. Ophthal., 33, 513

CARBONELl, L. M. (1971) The pathological anatomy of mycoses in 'Handbuch der Speziellen Anatomie und

Histologie', by R. D. Baker, p. 38. Springer Verlag, Berlin, Heidelberg, and New York

DUKE-ELDER, S. (1974) 'System of Ophthalmology', vol. XIII, 'The Ocular Adnexa', part II, p. 766. Kimpton, London

FINE, M., and WARING, w. s. (1947) Arch. Ophthal. (Chic.), 38, 39

GRönvall, H. (1944) Acta Ophthal. (Kbh.), 21, 247

GUNDERSEN, T., personal communication quoted in: Garfin, S. W. (1942) Arch. Ophthal. (Chic.), 27, 167

JENSEN, O. A. (1974) Exp. Eye Res., 18, 417

JONES, L. T. (1965) Amer. F. Ophthal., 60, I I I

KOFLER, K. (1941) Klin. Mbl. Augenheilk., 106, 712

STERN, J. J. (1952) Amer. F. Ophthal., 35, 1206

WERB, A. (1971) Brit. F. Ophthal., 55, 559

WOLTER, J. R., and DeITZ, M. R. (1963) Amer. F. Ophthal., 55, I 53

-, STRATFORD, T., and hamell, E. R. (1956) Arch. Ophthal., 55, 320 